\title{
Cartografando Resolução de Problemas - O que há de/em/com práticas de Ensino de Matemática
}

Cartographying Problem Solving - What is happening with/within/in the Mathematics Teaching practices

Luiz Carlos Leal Junior ${ }^{1}$ Lourdes de la Rosa Onuchic ${ }^{2}$

\section{Resumo}

Considerando alguns pressupostos teórico-filosóficos que engendram práticas em Resolução de Problemas, objetiva-se realizar um estudo analítico acerca dos discursos que permeiam, engendram, potencializam e põem em funcionamento práticas, teorias, teorizações e outros discursos sobre a Resolução de Problemas. Para tanto, procedeu-se à análise do discurso pautada pela arqueogenealogia em Michel Foucault, enquanto uma caixa de ferramentas, para compor uma análise com o corpus desta pesquisa. A Resolução de Problemas encaixase na égide de uma metodologia, enquanto que, em outro panorama, ela pode ser concebida como algo mais amplo e complexo, que visa dar conta de campos, elementos e conceitos problemáticos e concernentes à Educação. Isso permite inferir, de alguma forma, que para entender a Resolução de Problemas com seus princípios, bases e propostas de pesquisa, educativa e educacional, faz-se extremamente necessário analisar seus pressupostos teóricos, pois são eles que the darão o tom de algo restrito ou amplo, uma metodologia ou uma filosofia. Contudo, tal concepção será sempre local e regional, sendo ela validada e legitimada pela comunidade que a prática.

Palavras-chave: resolução de problemas; pressupostos filosóficos; prática educacional em matemática; arqueogenealogia; análise do discurso.

\section{Abstract}

Considering some theoretical-philosophical tenants that engender practices in Problem Solving, the objective of this work is to perform an analytical study about the discourses that permeate, potentiate and running practices, theories, theorizations, and other discourses about Problem Solving. In order, it was proceeded to analyze the discourse guided by archeogenealogy in Michel Foucault, as a toolbox, to figure out an analysis with the corpus of this research. Problem-solving can fits into the aegis of a methodology, while in another scenario it can be conceived as something broader and more complex, designed to deal with problematic fields, elements and concepts concerning Education. This allows to infer, in some way, that in order to understand Problem Solving with its principles, bases and educational research proposals, it is extremely necessary to understand its theoretical presuppositions,

\footnotetext{
1 Instituto Federal de Educação, Ciência e Tecnologia de São Paulo | luizleal@ifsp.edu.br

2 Universidade Estadual Paulista Júlio de Mesquita Filho | Ironuchic@gmail.com
} 
since they are the ones that will give the tone of something restricted or broad, a methodology or a philosophy. However, such a conception will always be local and regional, being validated and legitimized by the community that practices and running it.

Keywords: problem solving; philosophical tenants; educational practice in mathematics; archeogenealogy; discourse analysis.

\section{Introduzindo e problematizando}

No idioma português, bem como em outros, encontramos diversas expressões que possuem significados diferentes. Essa dizibilidade é destacada em As palavras e as coisas de Michel Foucault (1999), quando o filósofo recorre a estudos da linguagem para expor que uma mesma expressão pode dizer de coisas diferentes e que, aqui, evidenciamos também no caso das expressões Resolução de Problemas e resolução de problemas, iniciadas por letras maiúsculas e minúsculas que, de fato, dirá de coisas diferentes, mas não antagônicas.

Como pesquisadores imbricados nessa temática, dedicamo-nos a estudar o assunto em algumas perspectivas realizando uma arqueogenealogia sobre discursos acerca de práticas que envolvem Resolução de Problemas e, consequentemente, propor uma cartografia dessa análise discursiva, a qual decorre de uma compilação primeiramente realizada em Leal Júnior (2018), em uma tese de doutoramento intitulada: Tessitura sobre discursos acerca de Resolução de Problemas e seus pressupostos filosóficos: Cosi è, se vi pare. O referido trabalho foi proposto enquanto uma análise de discurso arqueogenealógica que visa a pensar sobre o seguinte questionamento: Como práticas sobre Resolução de Problemas para o Ensino de Matemática têm sido evidenciadas em pesquisas?

\section{Articulações em fazeres e procedimentos - Itinerário de pesquisa}

De saída, faz-se necessário pensarmos sobre o que é fazer arqueogenealogia e como ela implica nessa cartografia. Contudo, destacamos que a cartografia não é o objeto primeiro da análise discursiva pretendida, ela se mostrou como um dos resultados possíveis para se olhar para nossa questão de pesquisa, uma caixa de ferramentas. Decorrente de Foucault (1999, 2014, 2015) e Veiga-Neto (2011), a arqueogenealogia é uma composição de alguns fazeres de pesquisa, como a arqueologia, a genealogia e a ética em Foucault. Trata-se de um movimento de pesquisa, enquanto que a arqueologia e a genealogia não se dão como movimento, elas atuam sobre corpos e sobre as práticas que envolvem estes corpos. A arqueologia foucaultiana é uma forma de estudos e pesquisas que atua sobre os discursos de forma analítica, ela se dedica à relação ser-discurso e à análise do discurso. No segundo campo, o da genealogia, enquanto ato de pesquisar, ele está estabelecido em torno da relação poder-saber e vai em busca de entender a constituição do sujeito da ação sobre outros. Fará isso interrogando e problematizando o surgimento de algo relacionando saber e poder.

No último campo que compõe a arqueogenealogia, aquele da ética, que é atravessado por influências dos primeiros campos e centrado na relação ser-consigo, ou no cuidado de 
si, visa-se a compreender o sujeito da ação sobre si. Nesse movimento, problematiza-se a própria subjetividade e, por isso, muitos autores de estudos foucaultianos preferem falar de três domínios de Foucault, mas isso não será nosso foco.

Em nosso trabalho, bem como no de Leal Junior (2018), os discursos que nos dispusemos a analisar, seus enunciados, enunciações e dizibilidades são decorrentes de um questionário aberto enviado a pesquisadores nacionais e internacionais do tema que foram bastante referenciados em pesquisas apresentadas nas três primeiras versões do Seminário de Resolução de Problemas, realizados na UNESP, e nos proceedings do XIII ICME, realizado na Alemanha. As perguntas-chave da pesquisa que enviamos aos mesmos foram colocadas da seguinte forma, onde os eles poderiam sentir-se à vontade para responder como bem quisessem:

1. Segundo sua perspectiva, o quê ou com o quê as teorizações sobre a Resolução de Problemas têm contribuído para se pensar a Educação Matemática?

2. Como nós educadores/pesquisadores poderíamos trabalhar a matemática em sala de aula pautados por princípios ou proposições advindas da Resolução de Problemas? Você pode dar um exemplo?

3. Como você percebe, através de pressupostos da Resolução de Problemas, questões como: A sala de aula de matemática; conhecimento matemático; ensino, aprendizagem e avaliação de Matemática; sociedade; e Conceitos?

4. Você percebe alguma relação entre Filosofia da Educação Matemática e Resolução de Problemas?

5. Que outras considerações você poderia fazer sobre Resolução de Problemas e Filosofia da Educação Matemática?

Fonte: Os autores.

As questões acima remontam a uma percepção relacional entre Resolução de Problemas e Filosofia da Educação Matemática, o que foi posto propositadamente, pois, segundo Leal Junior (2018) e Possamai, Cardozo e Meneghelli (2018), é um campo de estudos que reflete muitos dos pressupostos que permeiam práticas de Resolução de Problemas. Os pressupostos dessa prática nem sempre estão explícitos em trabalhos de pesquisa acerca do tema e, pelo fato de a Filosofia se dispor a trabalhar questões em torno de pressupostos, trazendo-os à tona, uma vez que são fundamentais para se entender os discursos que perpassam tais práticas..

Não estamos interessados na identificação dos sujeitos entrevistados, pois, numa perspectiva foucaultiana, não nos interessa focar no sujeito depoente nem de sua interioridade essencial, em sua identidade, ou da captação superficial de sua verdade, pois esse sujeito consiste em uma fabricação da modernidade, mas queremos focar em suas dizibilidades. Posto que, o discurso, em Foucault, apresenta-se como um "campo de regularidade para diversas posições de subjetividade", que nos permite buscar "na rede de discursos, os fios que constituíram, em uma trama histórica, a produção de sujeitos", como destacam Souza e Fonseca (2010, p. 44). Todavia, informamos que trabalhamos com discursos de dez pesquisadores de países como Brasil, Israel, Estados Unidos, Dinamarca e Reino Unido, que serão denominados de P1, P2, ... P7, os demais três serão nomeados por terem enviado trabalhos para responder às perguntas enviadas, quais sejam: Paul Ernest, Lourdes Onuchic e 
Norma Allevato, e devemos manter os critérios de citação de referências para os mesmos. Outrossim, nem todos os discursos são trazidos neste trabalho, na íntegra, dadas suas extensões. Mas, procuramos expor um panorama dos contextos que Ihes permitiram avançar em pesquisas sobre o tema mesmo que em termos de referenciais teóricos ou citando trechos de suas entrevistas.

Assim, analisando práticas de Resolução de Problemas, evidencia-se que elas não visam trabalhar sob as imposições sistemáticas que se lhe colocam, mas miná-las a ponto de que não resistam às tensões produzidas e uma nova proposta educacional de ensino, de aprendizagem e de avaliação emerjam focando no que deve ser aprendido em detrimento do que deve ser ordenadamente ensinado. Uma vez que as imposições de conteúdos estão postas a fim de permitir apenas a circulação de algumas políticas de verdades, ou seja, que apenas alguns conteúdos sejam veiculados. Assim, é mister pensarmos estes atos, essas políticas e todos os outros elementos desses campos a partir de outros territórios que não aquele da sala de aula, da escola, ou de um campo restritivo, mas como propõe a arqueogenealogia, precisamos desterritorializarmo-nos para poder ver a gama de forças, valores e problemas que permeiam este sistema.

Na esteira dessa ideia, o GTERP - Grupo de Trabalho e Estudos em Resolução de Problemas - visa a aprendizagem como uma visão mais holística sobre conceitos e não conteúdos, permitindo que os alunos possam enxergar, em seu entorno, como foram constituídos sujeitos daquele cenário e o porquê que aquela matemática lhes será importante. Entretanto, eles também são levados a pensar em que outras matemáticas poderiam envolver-se, como esta matemática chegou a esse ponto e para onde mais ela pode avançar. Não é interessante, nesse viés, focar somente a matemática, mas as relações que ela tem com outras componentes curriculares e, além disso, com a vida em sociedade, o que é bastante desafiador, porém extremamente necessário (PINHEIRO; LEAL JUNIOR; FERREIRA, 2017).

A expressão resolução de problemas refere-se ao ato de resolver problemas ou situações-problemas, algo que pode ser esporádico ou momentâneo, uma atividade de cunho recognitivo e puramente heurístico, que vise à exploração pontual de problemas matemáticos. Já a expressão Resolução de Problemas diz de uma prática institucionalizada ou um movimento educacional, algo que acontece em atividades e perpassa todo um movimento educacional e, por sua vez, ultrapassa os limites impostos pelo tempo e pelo espaço, extravasando as paredes da escola, problematizando a vida de alguma forma (LEAL JUNIOR; MISKULIN, 2017). No idioma inglês esse problema de interpretação pode ser contornado através de expressões como Problem Solving e solving problem. Tais termos serão problematizados neste trabalho, não porque todos os discursos tomem cuidado nessa diferenciação etimológica, mas, sim, porque há discursos que tomam esses termos como entes diferenciados, a exemplo dos trabalhos do GTERP, sobre os quais nos debruçamos adiante.

Note-se que, até mesmo a expressão Resolução de Problemas apresenta outros significados e significados outros e, por isso, indicamos uma compreensão através da palavra prática ou movimento, em um sentido alargado que possa abranger a potência dessa terminologia. Stanic e Kilpatrick (1989) expõem que essa prática de Resolução de Problemas pode ser compreendida de algumas formas que não se encaixariam na resolução de 
problemas. Contudo, a resolução de problemas é o cerne e o mote de qualquer proposta de Resolução de Problemas.

Muitas pesquisas apontam que a Resolução de Problemas se consolidou como uma prática de desenvolvimento social e de construção e desenvolvimento do conhecimento, não só no âmbito da matemática, mas também em outros campos de estudos como física, filosofia, psicologia, antropologia e etc. Focando nosso olhar sobre a perspectiva que serve à matemática e à Educação Matemática, procedemos nossa análise do discurso a partir do corpus de nossa pesquisa, olhando também para outras fontes que se relacionam e thes servem de suporte. Não há datas específicas para se começar a falar em Resolução de Problemas como um discurso institucionalizado. Porém, desde que as pessoas passaram a ter a necessidade de comunicar-se, comercializar produtos e desenvolver suas sociedades, entende-se estarmos diante de uma situação de resolução de problemas ou, até mesmo, de Resolução de Problemas (ALMEIDA, 2017; POSSAMAl; CARDOZO; MENEGHELLI, 2018).

Uma grande parte deste trabalho está pautada sobre os discursos escritos, os materiais impressos, livros, artigos e proceedings, com os quais apresentamos um pano de fundo para, posteriormente, articulá-los junto aos depoimentos. Poder-se-á perceber que nos colocamos enquanto analistas e problematizadores de discursos através de articulações dos mesmos e de pesquisas de nossa autoria, previamente divulgadas em periódicos ou livros, como forma de reificar nossa participação na formação discursiva proposta, respeitada a essência e a fundamentação do tema evocado.

Diante da multiplicidade de perspectivas que se lançam sobre e com a terminologia Resolução de Problemas, torna-se imperativo que os sujeitos pesquisadores explicitem suas percepções e os campos de onde falam. Conforme já apontado por Leal Junior e Miskulin (2017), no âmbito da Educação Matemática, a Resolução de Problemas se constitui um campo multifacetado e bastante retalhado, que pode apresentar confluências e, até mesmo, divergir dependendo da fundamentação teórica imbricada na prática educacional. Daí, decorre o interesse na escrita desta pesquisa e na estruturação de seus objetivos, a de apresentar uma tecitura acerca dos discursos que lhes sustentam e são veiculados no cenário acadêmico, como vimos compilando, aqui, da pesquisa de Leal Junior (2018).

\section{Resolução de Problemas: O que há?}

Na esteira dessas considerações, faz-se necessário olharmos para algumas primeiras concepções sobre a terminologia em questão para entendermos como, onde, quando e porquê chegamos a ter, nos discursos levantados, essa diversidade e a possibilidade de uma tecitura com os mesmos. Por tal diversidade de visões e concepções para a prática educacional, realizada em torno da Resolução de Problemas, Onuchic, Leal Junior e Pironel (2017b) destacam que ela se mostra perspectivamente como um movimento, fenômeno ou regularidade discursiva.

De acordo com Àvila (2004), a história da Resolução de Problemas, no âmbito da matemática, funde-se com a própria História da Matemática e, que no campo da Educação Matemática, ela se mostra diante de seu papel unificador, atravessando os processos de ensino e de aprendizagem, além de apresentar-se como uma interface entre teoria e prática, 
uma base para estudos e aplicações desde a pesquisa até a prática educacional, como defendem também Leal Junior et al. (2014).

Pensar a Resolução de Problemas restrita à matemática é a forma como se tem trabalhado essa vertente nas pesquisas de diversos grupos no Brasil e no mundo. Dessa forma, entram em jogo outros campos de conhecimento humano, como a psicologia que se dedica a estudar a (Re)Solução de Problemas como uma atividade de cunho cognitivista ou uma forma de desenvolvimento humano, onde a matemática pode constituir-se como um subcampo de estudos à psicologia (ANDRADE, 2009), perspectiva esta bastante trabalhada pelo GTERP em Onuchic, Leal Junior e Pironel (2017b). Nessa processualidade ela ganha contornos de um meio de produção do conhecimento matemático que é explorado por diversos campos e que, sobretudo, é uma maneira de produção de valores em todas as esferas da vida humana (MACHADO, 2015).

Desde Platão e Aristóteles já se tem indícios de uma prática educativa de matemática e filosofia pautadas pela Resolução de Problemas enquanto movimento problematizador do mundo e de produção de conhecimento, o qual muitos campos de estudos da atualidade denominam de problematização, e que tomam a Resolução de Problemas como o cerne do ensino de matemática e de seu desenvolvimento (MACHADO; D'AMBRÓSIO; ARANTES, 2014).

A questão em torno da problematização é bastante ampla. Pois, baseado nos estudos supracitados, ela envolve um pensar que transcende a própria matemática e a filosofia, valendo-se delas, pois possui caráter epistemológico, ontológico, político e axiológico. Assim, falar sobre ensino nos coloca no território da epistemologia, a qual vai buscar por elementos essenciais ao que conhecemos, ao conhecimento, aos saberes e, consequentemente, ao ensino e à aprendizagem (FERREIRA; ALENCAR, 2018). Para o GTERP a problematização tem a ver com a instauração de campos problemáticos a partir de conceitos e problemas no e para o ensino de matemática, ou seja, um campo em que o ensino aconteça através da Resolução de Problemas e a aprendizagem seja potencializada por meio dessa prática. Esses elementos estão imbricados na constituição do que somos, enquanto seres conhecedores e que se desenvolvem à medida que conhecem, constituindo-se enquanto sujeitos sociais, o que vai apontar para a ontologia, conforme propõem Wagner e Silveira (2017).

Entretanto, a Matemática Escolar ou o Ensino de Matemática também trazem à tona questões e procedimentos de transmissão de valores. E, pregam os últimos autores supracitados, quantidades e processos de resolução de problemas comunicam procedimentos e valores que são próprios de seu campo, como vai corroborar o pesquisador P6, em seu discurso presente no trabalho de Leal Junior (2018). Elementos como quantidades e quantificações são exemplos de mensuração e de valoração que estão relacionados às culturas. Isso porque a matemática vem sendo utilizada como um meio de produção de valores nas sociedades, que transferem isso às suas práticas cotidianas de relacionamento entre os seres, o que confere a essa perspectiva de Resolução de Problemas um relacionamento direto com a axiologia.

Esta proposição é a motivação apontada pelos Parâmetros Curriculares Nacionais (PCN) (BRASIL, 1998) como ponto de partida da atividade e do ensino de matemática, e que permanece como eixo estruturador da BNCC, como apontam Morais, Onuchic e Leal Junior (2017) e Brasil (1997, 1998, 2000, 2017). Em Brasil (1998, p. 20) podemos evidenciar que a visão 
norte-americana dos Standards 2000 teve influência sobre a proposta de uma matemática pautada pela resolução de problemas no Brasil em termos de ideais.

Em 1980, o National Council of Teachers of Mathematics. NCTM ., dos Estados Unidos, apresentou recomendações para o ensino de Matemática no documento .Agenda para Ação.2. Nele a resolução de problemas era destacada como o foco do ensino da Matemática nos anos 80. Também a compreensão da relevância de aspectos sociais, antropológicos, linguísticos, além dos cognitivos, na aprendizagem da Matemática, imprimiu novos rumos às discussões curriculares. Essas ideias influenciaram as reformas que ocorreram em todo o mundo, a partir de então. As propostas elaboradas no período 1980/1995, em diferentes países, apresentaram pontos de convergência, como: direcionamento do ensino fundamental para a aquisição de competências básicas necessárias ao cidadão e não apenas voltadas para a preparação de estudos posteriores; importância do desempenho de um papel ativo do aluno na construção do seu conhecimento; ênfase na resolução de problemas, na exploração da Matemática a partir dos problemas vividos no cotidiano e encontrados nas várias disciplinas; importância de trabalhar com amplo espectro de conteúdos, incluindo já no ensino fundamental, por exemplo, elementos de estatística, probabilidade e combinatória para atender à demanda social que indica a necessidade de abordar esses assuntos; necessidade de levar os alunos a compreender a importância do uso da tecnologia e a acompanhar sua permanente renovação. Essas ideias vêm sendo discutidas no Brasil e algumas aparecem incorporadas pelas propostas curriculares de Secretarias de Estado e Secretarias Municipais de Educação, havendo experiências bem-sucedidas que comprovam sua fecundidade (BRASIL, 1998, p. 20).

A respeito desse eixo estruturador, os autores entendem que tanto os PCN quanto a BNCC são percepções de uma educação pautada pela resolução de problemas, de uma educação que visa oferecer aos alunos modos de mobilizar conhecimentos e de desenvolver habilidades e competências para gerenciar as informações, mesmo que elas digam de coisas diferentes. Nos PCN e na BNCC, bem como em outros trabalhos que tratam do tema, não há uma discriminação em torno da expressão (r)Resolução de (p)Problemas que diferencie seus conceitos, ficando a cargo do/a leitor/a identificar quando se fala de uma atividade e quando se fala de uma prática, por exemplo.

Assim, trazemos à tona a relação da Resolução de Problemas com a prática em sala de aula. Sobre isso, o pesquisador P02 pontua que a Resolução de Problemas está intimamente ligada a ação e a prática em sala de aula e constitui-se enquanto uma ação sobre os acontecimentos da atividade educacional, além de ser prioridade em salas de aulas de matemática, uma vez que dinamiza e promove o ensino e a aprendizagem dessa componente curricular. Para ele, questões que envolvam essas considerações são sempre difíceis de se responder. Embora seu cenário seja diferente do brasileiro, há muitas confluências com o que temos percebido na intencionalidade desse movimento.

Ele assesta,

Eu gosto de pensar que aqueles de nós que trabalharam em questões relacionadas com a resolução de problemas em matemática têm 
influenciado diretamente o pensamento da maior comunidade de educação matemática, mas eu não posso fazer essa afirmação com certeza. Parece-me ser como o enigma "ovo e a galinha" - Qual veio primeiramente? Assim, teorizando sobre a resolução de problema ou sobre a mudança gradual dentro da comunidade da instrução da matemática? Como um todo sobre a natureza da matemática? Como é aprendida? E, como deve ser ensinada? Eu suspeito que cada um tem contribuído para o outro: Pesquisador P02 em (LEAL JUNIOR, 2018, p. 78, tradução nossa)³.

Assim, recorrendo a estudos do GTERP sobre o mesmo tema, percebemos que essas confluências nas propostas são trabalhadas mesmo em meio às dificuldades de encarar questões críticas, como tempo de aulas, currículos e processos avaliativos. Também, decorrente da pesquisa de Morais, Onuchic e Leal Junior (2017), podemos perceber que a Resolução de Problemas ou a resolução de problemas podem ser vistas de muitas formas, inclusive como uma matemática para ser ensinada. Podemos, então, destacar o caráter pedagógico dessa prática de Resolução de Problemas, isto é, concebendo-a enquanto uma Pedagogia da Matemática. Note-se que não estamos usando o termo didática, mas pedagogia, como problematizaremos aqui.

A partir de Ernest (1991, 1992, 2011), entrevistado, que é nomeado por ter enviado trabalhos para nossa análise, um pesquisador imbricado nos temas Resolução de Problemas e Filosofia da Educação Matemática, antes de se falar em Resolução de Problemas precisamos, acima de tudo, pensar sobre o papel dos problemas a partir de suas propostas constitutivas, as quais estão intrinsecamente relacionadas às crenças dos/as praticantes e influenciadas por propostas advindas da Filosofia da Matemática e no Construtivismo Social.

Para ele, as funções e objetivos dos problemas estão idiossincraticamente ligados aos objetivos visados para o ensino e à aprendizagem da matemática e com a forma como o professor interpreta tanto os problemas quanto a metodologia de ensino. Sobre isso, o Pesquisador P01 diz que esta prática está diretamente relacionada às crenças dos professores e pesquisadores: "Minha crença no primado da resolução de problemas pode ser considerada como uma parte importante da minha própria filosofia de matemática". (LEAL JUNIOR, 2018, p. 79, tradução nossa).

Entretanto, na perspectiva do pesquisador inglês, a Resolução de Problemas é uma lente com a qual se pode olhar o ensino de matemática tendo como mote a aprendizagem dos alunos. Não se trata de algo certo e concreto, mas algo que acontece por meio da prática e no momento da mesma prática. Ele e o GTERP entendem que a Resolução de Problemas, na maioria das vezes, repousa sobre filosofias pessoais ou crenças de alunos e professores, e pode organizar e orientar a atividade de resolução de problemas na sala de aula, que é percebida contextual e perspectivamente.

Deste modo, a compreensão da problemática em torno da (R)resolução de (P)problemas perpassa uma análise simplista sobre meios e fins no âmbito da Educação Matemática, como assegura Boavida (1993). Diante disso, essa problemática poderá ser alargada pela análise dos

\footnotetext{
${ }^{3}$ Este discurso foi traduzido do idioma inglês, e sua versão original pode ser conferida na referência indicada. Tais discursos, sempre que referenciados pela expressão 'tradução nossa', vêm do idioma inglês e, aqui, apenas expomos a tradução para não ultrapassar os limites de escrita.
} 
possíveis papéis que a resolução de problemas poderá assumir, quando atravessada pela influência de fatores sociais e políticos, como escola e currículo. A teorização de Ernest sobre Resolução de Problemas avança ao passo que trabalha a influência da resolução de problemas (como atividade), enquanto eixo norteador da Resolução de Problemas (enquanto prática) pautada pela influência do Construtivismo Social, da Ética e da Filosofia da Educação Matemática, que são também compartilhadas com o Pesquisador $\mathrm{P05}^{4}$, que o menciona como o referencial de sua concepção para um trabalho nessa perspectiva. Sendo que, para eles, a Filosofia da Educação Matemática consiste na união da Filosofia da Matemática e da Educação, mais precisamente no que concerne ao Ensino de Matemática e suas práticas.

No contexto de P07 e Blaire (1981), uma vertente bastante forte em suas pesquisas é que a ênfase dessa prática é posta nos alunos e nos seus interesses, podendo ser contextualizada socialmente ou não, o que depende, em muito, das crenças e interesses da instituição. Eles justificam que isso é reforçado quando há uma gama de temas para se explorar e fica-se à mercê do tempo da aula, ou quando o ato de investigar está restrito às situações puramente matemáticas ou tópicos temáticos. Eles asseguram que a Resolução de Problemas deveria ser algo mais fluido, que permitisse aos sujeitos do cenário educacional investigar e problematizar, de maneira mais completa, o ensinar e o aprender matemática. Fazem isso, trazendo para o âmago da atividade educativa problemas de cunho social e político para serem cruzados com os temas matemáticos, questionando modelos tradicionais e engessamentos institucionais, como rígidos programas curriculares.

Para tanto, devemos destacar que, sendo concebida dessa forma, a Resolução de Problemas torna-se um campo inter ou multidisciplinar e, a respeito da pesquisa em Resolução de Problemas, desenvolvida no seio da Educação Matemática, o pesquisador P04, corroborando as ideias dos pesquisadores ingleses, diz que

Então, a gente percebe, em algumas perspectivas do que tem sido dito sobre resolução de problemas, alguns elementos, alguns ingredientes que podem ajudar a entender o que é, ou como é que alguns pesquisadores têm entendido que seja o conhecimento matemático, ou a matemática que aparece na escola, ou a matemática que acontece em situações de ensino aprendizagem. Na pesquisa, em qualquer área que seja (vamos falar da pesquisa em educação matemática), eu acho que quem faz pesquisa em educação matemática não pode se desprender - até por conta daquilo que eu estava falando, sobre o nosso objeto ser interdisciplinar -, não pode se desprender desse contexto, desse diálogo entre várias disciplinas. Dessas coisas, eu ressaltaria, no caso, a filosofia: Pesquisador P04 em (LEAL JUNIOR, 2018, p. 80).

Essa ideia está bastante relacionada àquela expressa no livro de Charles e Silver (1989), intitulado The Teaching and Assessing of Mathematical Problem Solving promovido pelo National Council of Teachers of Mathematics - NCTM - com aporte na história das práticas matemáticas, em que os autores reúnem uma coletânea de artigos que abordam a influência da Resolução de Problemas em torno de sua prática em diversos contextos. Nessa obra, Stanic

\footnotetext{
${ }^{4}$ Colocamos, aqui, nossa análise das dizibilidades e das perspectivas arroladas por este pesquisador e pelos demais. Contudo, um leitor mais interessado poderá conferir na íntegra os referidos depoimentos em Leal Junior (2018). Fizemos isso para atender as limitações de edição de um artigo acadêmico.
} 
e Kilpatrick (1989) fazem muitas considerações sobre prática, inclusive realizam um histórico sobre a Resolução de Problemas. Eles recuperam coleções de problemas tanto de manuscritos egípcios datados de 1650 a.C. quanto de documentos chineses de 1000 a.C. que apontam para trabalhos desenvolvidos através da Resolução de Problemas desde a antiguidade, evidenciando que se trata de algo muito mais antigo do que simplesmente uma disciplina de pesquisa da atualidade.

Em trabalhos mais recentes, pudemos evidenciar a extrema influência de J. Dewey na sistematização e implantação dessa prática em instituições de pesquisa e ensino nos séculos XIX e XX. Como aponta Coelho (2009), essa perspectiva de trabalho sofre certo arrefecimento desde a década de 1930 até final da década de 1970, quando é retomada a partir dos anos 80, reforçando o que vimos falando sobre a participação de Dewey na institucionalização de discursos em torno da Resolução de Problemas e seus pressupostos filosóficos.

Essa tendência também teve reflexos no cenário brasileiro, mais especificamente, entre as décadas de 1950 e 1960, quando as pedagogias progressistas de cunho pragmatista começaram a impactar nosso sistema educacional, sobre o qual Coelho (2009) afirma que "pouco se efetivou em termos de desenvolvimento de propostas e práticas curriculares baseadas em resolução de problemas nos termos propostos por Dewey". Acreditamos que o contexto político de propostas educacionais, pelo fato de serem diferenciados - Brasil e EUA, tenha contribuído para se gerar uma vertente de Resolução de Problemas, aqui no Brasil, que não conseguia estabelecer-se em termos de uma educação pautada pela resolução de problemas, configurando-se apenas como um rótulo nos parâmetros educativos brasileiros. Enquanto, naquela mesma época, era a ênfase do sistema norte-americano.

O movimento de estruturação educacional dos anos 90 iniciou-se no exterior, nas escolas médicas de McMaster (Canadá) e de Maastricht (Holanda), e ainda nas escolas de Albuquerque, de Harvard e do Havaí (Estados Unidos), entre outras. Mais recentemente, diversas escolas vêm resgatando essa perspectiva pedagógica, tanto na educação básica quanto na profissional, além de avançar, mesmo que laconicamente, pelos trajetos do Ensino Superior (Ibid.). Perspectivas educacionais como a Modelagem Matemática, o Problem Posing, - Design Educacional, o PBL (Problem Based Learning), as Investigações Matemáticas, o trabalho colaborativo, a exploração de problemas abertos, o ensino de matemática via resolução de problemas entre outros, são práticas apoiadas nesse movimento de estruturação educacional que foi alavancado através de problematizações sobre problemas, propostas, conceitos e na busca por uma forma fundante de se aprender (LEAL JUNIOR; ALLEVATO, 2018). Entretanto, apenas algumas dessas farão parte das dizibilidades que emergem do corpus desta pesquisa, enquanto as demais, mesmo sendo importantes, não serão abordadas.

\section{Resolução de Problemas: o que está havendo}

Há muitos pensadores da Educação que têm influenciado a prática educativa no Brasil, Zanotto e De Rose (2003) apontam quatro autores representativos de abordagens diversas da problematização, como um campo maior que abarca a Resolução de Problemas como 
atividade de Ensino-Aprendizagems: Dewey, Saviani, Paulo Freire e Ausubel. Trata-se de propostas de naturezas e concepções diferenciadas, onde é importante perceber que tais abordagens metodológicas dependem da filiação filosófico-ideológica do autor, de quem as aplica ou realiza as mesmas. Como se tem destacado, o pragmatismo Deweyano teve seu auge na década de 1930, quando passou a propor uma educação estreitamente ligada às demandas concretas da vida social em torno de problematizações sempre contextualizadas, ao que o sistema norte-americano passou a denominar Resolução de Problemas (ANDRADE, 2009; CORRADI, 2014; DEWEY, 1910). Ao contatar suas obras, como aquelas que arrolamos em nossas referências, percebemos que a Resolução de Problemas implicitamente Ihe dirigia os pensamentos sobre propostas educacionais visando ensinos 'eficientes' e a aprendizagem como resultado desse processo.

O termo Resolução de Problemas não aparece com frequência em seus escritos, mas se identifica com aquilo que o filósofo chama de pensamento reflexivo. Essa proposta é, em essência, a base da 'pedagogia de problemas' que aponta para a produção e constituição do pensamento humano (DEWEY, 1910). Nos EUA, ao longo da historicidade que vem sendo construída através das entrevistas com pesquisadores daquele país, percebe-se que os educadores/as de matemática trabalharam muito para assumir o controle da educação matemática durante a década de 1970, quando o ensino era dirigido por posturas empirista e behaviorista. Com isso, ao conseguirem tal controle, eles tomaram uma postura de prática contrária àquela vigente, quando se começou a discutir posturas construtivistas e interacionistas.

Daí, despontou a prática da matemática via resolução de problemas, a qual veio à tona durante o período do Movimento da Matemática Moderna - MMM, bastante influenciado por ideias de George Polya, por meio de seus trabalhos: How to Solve It (POLYA, 1945), Mathematics and Plausible Reasoning e Mathematical Discovery: On Understanding, Learning and Teaching Problem Solving (POLYA, 1954, 1968). Todavia, o Pesquisador P01 aponta para a importância desses estudos em um trabalho pautado por uma perspectiva de Resolução de Problemas, mas, ao mesmo tempo, considera que,

Eu admiro muito os escritos de George Polya. Eu percebi que os esforços para sistematizar suas ideias, para que a maior capacidade de resolver problemas pudessem ser demonstrados estatisticamente não tiveram êxito. No entanto, eu recomendo ler seus livros para todos os interessados em matemática, ensino de matemática ou resolução de problemas. Consideroos inspiradores e exemplares: Pesquisador P01 em (LEAL JUNIOR, 2018, p. 82, tradução nossa).

A partir do referencial supracitado, a Resolução de Problemas apresenta-se como um meio de constituição da própria matemática, a qual, por sua vez, é um conhecimento a priori,

\footnotetext{
${ }^{5}$ Note-se que os autores fazem suas colocações a partir da relação indissociável entre ensino e aprendizagem apontada por Paulo Freire para justificar a utilização do termo ensino-aprendizagem. Para ele não existe ensino sem aprendizagem. A educação, como ensinamentos, é um processo dialógico, um intercâmbio constante. Nessa relação, educador e educando trocam de papéis o tempo inteiro: o educando aprende ao passo que ensina seu educador e o educador ensina e aprende com seu estudante. Para este pensador, dentro do processo educacional, estudantes e professores devem assumir seus papéis conscientemente - não são apenas sujeitos do "ensinar" e do "aprender" e, sim sujeitos com histórias e trajetórias singulares. (FREIRE, 1996).
} 
ou seja, nessa visão construtivista de Polya, ela não é criada, ela é descoberta, já existente e que pode ser trabalhada de formas diferenciadas a partir de sua dada estrutura. Possibilitando, assim, não uma construção de um conhecimento inaugural, mas, reconstruindo ou construindo um conhecimento já-pronto, porém novo para determinados indivíduos resolvedores de problemas, novo para aquele indivíduo com a Resolução de Problemas.

A Resolução de Problemas como forma de ensinar matemática emergiu na monografia "Uma agenda para a ação", publicada pelo NCTM nos Estados Unidos em 1980. J. W. Wilson foi um dos principais proponentes da prática da Resolução de Problemas como uma forma de ensinar matemática aos alunos. A epistemologia genética de Jean Piaget foi uma segunda força para a mudança durante o movimento de volta ao básico, de saída do MMM. Contudo, a influência de Piaget teve imbricações naquele movimento, principalmente porque as estruturas genéticas de Piaget serviam como raciocínio psicológico para o estruturalismo presente nos currículos daquele movimento, embora houvesse uma confusão entre tipos de estruturas: Pesquisador P03 em (LEAL JUNIOR, 2018, p. 85, tradução nossa).

A respeito da reverberação da Teoria de Piaget e da Resolução de Problemas de Polya, durante o Movimento de Matemática Moderna, bem como do sistema de educação que o sucedeu, o Pesquisador P03 relata que

A influência de Piaget tornou-se pronunciada durante o movimento de volta ao movimento básico através do trabalho de E. V. G. e L. S. no projeto, Interdisciplinary Research on Number (IRON). Mas a ênfase no IRON não estava nas estruturas genéticas de Piaget, nem na "matemática" de Piaget como ela veio a ser conhecida. Em vez disso, com base na epistemologia genética de Piaget, E. V. G. desenvolveu "Construtivismo Radical, um Caminho de Saber e Aprender" que L. S. e alguns de seus alunos usaram seu trabalho em pesquisa e ensino em educação matemática, onde a matemática dos alunos foi enfatizada. Assim, houve duas forças principais para a mudança durante as décadas de 1980 e 1990; A prática matemática da resolução de problemas com sua suposição de uma realidade matemática independente da mente, e o construtivismo radical com sua suposição de que a cognição é constitutiva. Esta última força era altamente compatível com a Associação de Educação Progressiva, organizada pelo filósofo John Dewey, autor de "A Criança e o currículo" entre outras obras. O trabalho de Dewey foi uma força de mudança durante a primeira metade do século passado. Em contraste com a influência primária do empirismo durante esse período de tempo, a defesa de Dewey foi 'Abandonar a noção de assunto como algo fixo e pronto em si, fora da experiência da criança; deixar de pensar na experiência da criança como também algo duro e rápido; Vê-lo como algo fluente, embrionário, vital; E percebemos que a criança e o currículo são simplesmente dois limites que definem um único processo'. A educação progressiva de Dewey compartilhou pouco com os métodos empiristas dominantes do ensino e da aprendizagem na primeira metade do século XX, nem era influente durante o movimento moderno da matemática. Em contraste, era compatível com a visão dos construtores radicais de conhecimento e aprendizagem com a ênfase em um estudante 
ativo e autorregulador. Além disso, usando a resolução de problemas como um método para ensinar matemática compartilhada na visão de Dewey da criança matemática ativa e interativa. Os construtivistas radicais, no entanto, diferiram do progressismo de Dewey e dos proponentes da resolução de problemas, na medida em que tinham como objetivo reconstituir a matemática escolar como "matemática escolar", baseada em parte na matemática dos alunos construída pelo adulto. Na "matemática escolar", o observador e sua matemática não desempenham o papel de Dewey como um limite de um único processo ao qual a criança se aproxima. Em vez disso, o observador [ou matemática do professor] serve na assimilação, interpretação, comunicação e provocação em interações em curso. Serve também na construção dos alunos de matemática e no estabelecimento de zonas de construção potencial e real dos alunos. Finalmente, serve na construção de situações de aprendizagem e de metas de curto e longo prazos relativos às atividades construtivas dos alunos. Incluindo 0 observador enfatiza processos sociais similares ao trabalho do construtivista social como H. B.: Pesquisador P03, em (Leal Junior, 2018, p. 85-6, tradução nossa).

Nessa esteira temos muitos deslocamentos do Construtivismo (piagetiano) para a Educação e alguns poucos para a Educação Matemática, de onde podemos mencionar Moro (2009), Leal Junior e Allevato (2018) e Vergnaud (1990). Inclusive, a primeira pesquisadora diz que,

As proposições adotadas da base piagetiana (a importância da atividade do sujeito na construção do conhecimento; a caracterização dos invariantes operatórios, o modelo de equilibração na dialética da interação, o lugar, nesse processo, da tomada de consciência da ação) trazem junto o reconhecimento de seus limites, a saber: o desinteresse de Piaget pela aquisição de conhecimentos escolares, pelo papel ali dos conteúdos desses conhecimentos, a par do interesse maior pelas estruturas evolutivas, pelas operações, sem destaque à evolução específica dos conhecimentos em situações específicas; a exagerada separação entre o conhecimento matemático e a realidade física (...). Para sua contribuição, parte Vergnaud (...) de algumas proposições de base, a saber: - o conhecimento tem função adaptadora; logo, um conceito só faz sentido para a criança em situaçõesproblema, sem que essa dimensão pragmática seja reducionista e signifique perda da dimensão teórica dos conceitos Afirma Vergnaud (1989-1990, p. 56): "a resolução de problemas é a fonte e o critério do saber operatório". - o estudo da aquisição dos conhecimentos na ótica psicogenética exige, não o exame em separado da construção de diversos conceitos, mas em domínios amplos, correspondentes às diversas situações de sua elaboração no tempo. - toda construção conceitual supõe a elaboração de um conjunto de representações simbólicas em inter-relação. Mas deve-se fazer a diferenciação entre o conceito e sua representação, entre os significados conceituais e os sistemas de significantes que os explicitam. A ausência dessa diferenciação em matemática traz, muitas vezes, a ideia de que os símbolos e as operações sobre eles são a essência do conhecimento matemático. Para Vergnaud (ibid.), um conceito se define com apoio no seguinte tripé: o conjunto de situações que Ihe dão sentido (referência); o conjunto de invariantes que constituem suas propriedades (significado); o 
conjunto de formas simbólicas ou linguísticas que permitem suas representações (significante) (Moro, 2009, p. 130-1).

Por sua vez, no cenário brasileiro, Saviani recorre a uma concepção mais próxima da Teoria de Vygotsky ou da base Histórico-Dialética que a compõe, onde a problematização deve participar da constituição do sujeito, isto é, que o mesmo seja coautor da produção ou construção do conhecimento que se lhe é disposto. Tal teorização brasileira ganha corpo junto a conceitos advindos do materialismo histórico-dialético, que exigem, em sua natureza de estudos, requisitos como: radicalidade, rigor e uma crítica política e social diante da globalidade, dialeticamente problematizados e articulados entre si, com ênfase nas relações intra e intersubjetivas que constituem o 'sujeito cognoscente'(COELHO, 2009).

Essa mesma autora coloca ainda que Paulo Freire ressalta, assim como Dewey, a importância de tratar e atuar sobre origem real dos problemas propostos, e "destaca a necessidade de um compromisso com a transformação da realidade estudada, pela ação do sujeito. Daí, sua ênfase recair sobre o 'sujeito práxico', enfatizado pela abordagem sociocultural". Na perspectiva cognitivista enfatiza-se o 'sujeito aprendente', que será "aquele que aprende a aprender. Dentre outros autores que trabalham nessa perspectiva, Ausubel ressalta a importância do desenvolvimento de capacidades mentais ou cognitivas e defende que a ação de problematizar é passível de aprendizagem e que, nesse processo, desenvolvem-se níveis altamente elaborados de atividade cognitiva" (COELHO, 2009).

Outrossim, uma 'pedagogia de problemas' implica na construção de um currículo baseado em problemas, a qual perpassaria todo processo ou processualidade constituinte, como aquelas atividades que compõem uma prática de Resolução de Problemas, apontadas por Leal Junior e Onuchic (2015), que vai da invenção do problema à formalização dos conceitos envolvidos, e da atividade de resolver problemas pelo discente à formação do docente através da Resolução de Problemas. Isso se desdobra em uma proposta formativa centrada na Resolução de Problemas. Essa abordagem vem a ser o eixo balizador da organização dos tempos e espaços escolares, das disciplinas e das relações sociais no processo educativo. Tal abordagem implica uma organização multidisciplinar do currículo, confrontando os estudantes com situações-problema, modelando as atividades com que os alunos poderão deparar-se no dia a dia.

Tomando e entendendo a Resolução de Problemas como uma Pedagogia na/da Matemática, a Fundação Fiocruz propõe alguns princípios balizadores dessa prática com vista à aprendizagem, que tangenciam aqueles propostos pelo GTERP em seu primeiro livro, Resolução de Problemas: Teoria e Prática (ONUCHIC et al., 2014), quais sejam: a aprendizagem passa a ser cumulativa: nenhum tópico é abordado de forma completa e definitiva, mas sim reintroduzido repetidamente; a aprendizagem deve ser integrada: os conteúdos não devem ser apresentados isoladamente, mas disponibilizados para estudo na medida em que se relacionam ao problema; a aprendizagem passa a ser progressiva: as habilidades requeridas vão-se transformando à medida que os alunos amadurecem; e, a aprendizagem passa a ser consistente, quando os objetivos da aprendizagem, baseada em problemas, deverão ser operacionalizados nas diversas facetas do currículo, como, por exemplo, na relação entre ensino e avaliação. 
Voltando-nos à 'técnica de problemas' e, concordando com a autora supracitada, ressaltamos que tal prática tem sido considerada como aplicação arbitrária, esporádica e aleatória de estratégias, recursos, métodos e procedimentos conscientes e intencionalmente organizados em torno de uma determinada situação-problema. É algo que independe da organização curricular, e está diretamente associado a aplicação da lógica que atravessa a resolução de problemas como estratégia de ensino-aprendizagem.

Com efeito, precisa-se distinguir e destacar, a todo momento, que surgem compreensões e perspectivas distintas sobre o que se tem entendido por problemas e exercícios, o que torna tal discussão pedagogicamente relevante. Até aqui, em essência, problema continua confluindo para a definição de Onuchic e Allevato (2011, p. 81) onde problema é "tudo que não sabemos, mas que estamos interessados em fazer". Ora, tal concepção se difere da definição de exercício, que "seriam atividades de aprendizagem para as quais o sujeito já dispõe das estratégias de resolução e, então, as aplica às situações propostas" (Ibid.).

Essa vertente de técnicas de problemas está bastante próxima daquela de treinamento, quando o aluno é exposto a uma gama de problemas visando adquirir habilidades e técnicas de resolução para alcançar uma resposta. Isso para que ele possa reconhecer, através de leituras de problemas, que ou quais técnicas são necessárias para resolvê-lo. Entretanto, esse item limita-se a encontrar uma solução, não tendo cuidados com a aprendizagem e a problematização de conceitos matemáticos. Tal perspectiva assemelha-se, em muito, com aquelas desenvolvidas em cursos pré-vestibulares, que visam tornar os alunos resolvedores de problemas, mas não possibilitam abranger e criar uma matemática para além de heurísticas.

Outra variante dessa metodologia, ou dessa pedagogia, é a da 'problematização', note que esta palavra é bastante emblemática no contexto de Resolução de Problemas, uma vez que ela pode caracterizar uma metodologia, uma etapa da Resolução de Problemas, um campo mais amplo de estudos ou um movimento educacional, mas sua significação é, muitas vezes, negligenciada pelos pesquisadores. Na perspectiva de problematização de Berbel (1998), o problema advém da participação ativa dos alunos em problematizar a própria matemática. O problema passa a não ser, obrigatoriamente, responsabilidade do docente, mas será uma criação e invenção de professores e alunos, a partir da observação da realidade social por parte dos mesmos.

Percebe-se, então, uma postura que exige a experimentação da resolução de problemas na prática do dia a dia, embasados por conceitos estabelecidos e programados com o professor. Ainda que o nome e a proposta se mostrem adversos ao que se tem apresentado, essa problematização cabe no âmbito da Resolução de Problemas proposta por Allevato e Leal Junior (2014). Essa proposta amplia, para além da estrutura de Polya, uma perspectiva de Resolução de Problemas no Ensino de Matemática ao inserir a problematização por parte dos alunos e a resolução de problemas abertos, como mais possibilidades de trabalho didáticopedagógico. Apontando assim, para uma didática‘ em Resolução de Problemas, como uma

\footnotetext{
${ }^{6}$ A pedagogia é academicamente percebida e trabalhada enquanto ciência da educação e é composta de linhas de forças, ou 'braços' de estudos educacionais como a epistemologia, a psicologia da educação e a didática. Esta última é concebida enquanto uma vertente da pedagogia, uma área de estudos pedagógicos dedicada a estudar
} 
prática a partir da pedagogia que visa atuar sobre meios educativos e educacionais, visando a construção do conhecimento matemático através de problemas abertos, como têm trabalhado Allevato e Vieira (2016).

Essa problematização também é percebida em trabalhos que emergem da Educação Matemática Crítica, como aqueles apresentados por Skovsmose (2014, 2016), onde estudos sociais, contextuais e de interesse de uma comunidade tornam-se foco e mote de problemas, que trarão consigo conceitos relacionados ao tema principal. A partir daí, os próprios alunos poderão identificar dificuldades, carências, conceituações prementes, discrepâncias que devem ser problematizadas e analisadas colaborativamente, potencializando uma intervenção prática. Nessa vertente, podemos destacar que a abordagem crítica não é pontual nem generalizável, ela ressoa entre outras perspectivas que têm a Teoria Crítica como base de seus estudos. Podemos, aqui, recorrer a um exemplo que faz parte de nosso corpus a respeito do tema evocado. Compilamos, então, uma parte do trabalho de Leal Junior e Allevato (2018), quando trazem para o centro de suas discussões uma das aplicações da Pedagogia de Paulo Freire, que nos permite olhar a Resolução de Problemas como uma Pedagogia de Problemas, ou como se queira, uma prática pedagógica baseada em problematizações, ou deslocamento do conceito freireano de Pedagogia da Pergunta.

Para esses pesquisadores, a Resolução de Problemas é posta um movimento de subversão ao sistema tradicional e enciclopédico de ensino; a aprendizagem é o foco dos processos educacionais e as perguntas, problemas e questionamentos são os agenciadores da produção do conhecimento. Essa pedagogia (da pergunta) está voltada para o diálogo como instrumento possibilitador, elemento responsável por tal forma libertadora da educação, posto que "a educação é uma construção constante que é feita por educadores, em conjunto (com seus alunos) e dialogicamente" (CARNEIRO, 2013, p. 84).

A Resolução de Problemas opõe-se a uma pedagogia de concessões de respostas, como transmissão do conhecimento definido a priori e baseado em respostas concretas e fechadas, onde não há espaço para o questionar, o interrogar, o investigar, o discutir e o explorar. Emerge daí um outro conceito discutido por aqueles sujeitos, o do Momento Pedagógico7, o qual vai interceptar, naquela visão, a Pedagogia da Pergunta e a Resolução de Problemas, constituindo "uma forma libertadora de educar, que é uma maneira de ensino aberto a novos horizontes, por dar oportunidade para o educando de intervir, dar sua contribuição para o ensino de forma dialógica entre professor e aluno" (Ibidem, p. 84).

Então, interrogar, questionar e produzir ou construir conhecimento matemático são ações essenciais para promover o ensino e efetivar uma aprendizagem. Nessa prática, ao ser interrogado pelos alunos que expõem suas dúvidas, o professor não fornece respostas

os fenômenos educacionais. Trata-se de um campo que vem sendo modificado diante das mudanças e desenvolvimentos sociais que afetam a educação e, consequentemente, acabam por re-significar o que é didática (PIMENTA, 2000).

7 Trata-se de um conceito de P. Meirieu, o qual traduz os acontecimentos de sala de aula, que se estabelecem quando há produção ou construção de um conhecimento, quando se potencializa a aprendizagem, mediante a percepção de que somos impotentes em consolidar efetivamente, por nós mesmos, uma aprendizagem. Isso, considerando que "[...] apenas o reconhecimento de nossa impotência educativa permite-nos encontrar um verdadeiro poder pedagógico: o de autorizar o outro a assumir seu próprio lugar e, com isso, a agir sobre os dispositivos e os métodos; o de lhe propor saberes a serem apropriados, conhecimentos a serem dominados e pervertidos, que talvez lhe permitam, e quando ele decidir, 'fazer-se a si mesmo'". (MEIRIEU, 1995, p. 289). 
prontas, mas apresenta novos questionamentos, problematiza as próprias perguntas, potencializando pensamentos outros a seus alunos. Para Meirieu (1995) e Freire e Faundez (1985), e também para nós, se desviarmos o foco do que deve ser ensinado para o que deve ser aprendido, podemos seguir para o desenvolvimento de competências e potencialidades na e com a matemática, que vão de encontro à postura hegemônica e hermética da escola tradicional e do professor conhecedor - promotor de momentos pedagógicos inseguros e improdutivos. De fato, o verdadeiro Momento Pedagógico somente pode acontecer quando professor e alunos tomam consciência de sua impotência educativa.

Um Momento Pedagógico é aquele em que o aluno toma consciência de que tem potencial para construir ou produzir conhecimento e constituir sua aprendizagem; nesse contexto o professor deve agir como agenciador, o que pode ser feito através da Resolução de Problemas. Trata-se de um tema que tem se destacado com bastante força, mas de modo implícito, nas práticas docentes do momento e do movimento da Resolução de Problemas em aulas de matemática (LEAL JUNIO; ALLEVATO, 2018).

\section{Considerações finais}

Certamente muitas pessoas poderiam ler este trabalho e pensar que faltam perspectivas ou ver, estas aqui postas, sob outro prisma, mas essa ideia reforça aquilo que entendemos como uma arqueogenealogia, pois a multiplicidade de significações e de sentidos desta tessitura será, de fato, o leitor. Intentamos com o exposto orientar ao leitor sobre os objetos de nosso estudo, como eles se constituíram para nós e para os sujeitos pesquisadores que foram reificados no corpus de nossa pesquisa. De fato, há outras perspectivas tão importantes quanto essas presentes em nosso texto, mas por motivos que destacamos anteriormente, não foram incluídas em nossa análise. Todavia, procuramos adentrar na parte que equivale a regularidades discursivas e algumas políticas e vontades de verdades que perpassam a Educação Matemática em termos de práticas de Resolução de Problemas, onde analisamos os pressupostos das mesmas que vêm sendo veiculados nas pesquisas sobre o tema.

Seja enquanto Pedagogia de Problemas ou da Matemática, Didática, Momento Pedagógico, Prática da própria Matemática, desenvolvimento institucional de habilidades e competências em Matemática, heurística ou heurismos, treinamento, metodologias variadas ou alternativas, modelização ou, até mesmo, como uma filosofia da ou para a Matemática com viés no ensino, a Resolução de Problemas ainda é percebida como o mote de um ensino pragmático, abstrato, teórico ou aplicado da Matemática tanto no ensino básico quanto no superior, tanto no Brasil quanto no exterior. Isso dependerá, essencialmente, de quem a prática e das políticas que lhe servem de arcabouço.

\section{Referências}

ALLEVATO, N. S. G.; ONUCHIC, L. R. Ensino-Aprendizagem-Avaliação: por que através de Resolução de Problemas? In: AUTOR 2, L. R. et al. (Org.). Resolução de Problemas: Teoria e prática. Jundiaí: Paco Editorial, 2014. p. 35-52. 
ALLEVATO, N.; VIEIRA, G. Do ensino através da resolução de problemas abertos às investigações matemáticas: possibilidades para a aprendizagem. Quadrante, Lisboa, v. 25, n. 1, p. 113-131, 2016.

ALMEIDA, M. C. A Matemática na Idade da Pedra: Filosofia, epistemologia, neurofisiologia e pré-história. 1. ed. São Paulo: Livraria da Física, 2017. 642 p.

ANDRADE, E. N. F. O discurso de John Dewey sobre natureza humana e conduta: contribuições à psicologia e à educação. 2009.(Mestrado)-Departamento de Psicologia, Universidade de São Paulo, Ribeirão Preto, 2009.

LEAL JUNIOR, L. C. Tessitura sobre discursos acerca de Resolução de Problemas e seus pressupostos filosóficos em Educação Matemática: cosi è, se vi pare. Tese (doutorado). UNESP - Rio Claro. 2018, $352 f$.

LEAL JUNIOR, L. C.; MISKULIN, R. G. S. Perspectivas de Resolução de Problemas por meio de Articulações entre Teoria, Prática e Conceitos sobre Comunidade de Prática. In: ONUCHIC, L. R.; LEAL JUNIOR, L. C.; PIRONEL, M. (Org.). Perspectivas para Resolução de Problemas. 1. ed. São Paulo: Livraria da Física, 2017. cap. 11, p. 305-353.

ONUCHIC, L. R.; LEAL JUNIOR, L. C.; PIRONEL, M. Introdução ao Livro Perspectivas para Resolução de Problemas. In: ONUCHIC, L. R.; LEAL JUNIOR, L. C.; PIRONEL, M. (Org.). Perspectivas para Resolução de Problemas. São Paulo: Livraria da Física, 2017a. p. 13-20.

BERBEL, N. A. N. A problematização e a aprendizagem baseada em problemas: diferentes termos ou diferentes caminhos? Interface - comunicação, saúde e educação, v. 1, n. 2, p. 139154, fev. 1998.

BLAIRE, E. Philosophy of Mathematics Education. 1981. 284 f.(Doutorado)-Departamento de Educação, University of London, Londres, 1981.

BOAVIDA, A. M. D. R. L. Resolução de Problemas em Educação Matemática: Contributo para uma análise epistemológica e educativa das representações pessoais dos professores. 1993. 303 f.(Mestrado)-Ciências de Educação, Universidade de Lisboa, Lisboa, 1993.

BRASIL. Parâmetros Curriculares Nacionais. Brasília, 1997. 126 p. Disponível em: http://portal.mec.gov.br/seb/arquivos/pdf/livro01.pdf. Acesso em: 12/11/2017.

BRASIL. Base Nacional Comum Curricular. Brasília: Secretaria de Educação Básica, 2017. 396 p. Disponível em: http://basenacionalcomum.mec.gov.br/images/BNCC_publicacao.pdf>. Acesso em: 13/11/2017.

BRASIL. Parâmetros Curriculares Nacionais. Brasília, 1998.148 p. Disponível em:http://portal.mec.gov.br/seb/arquivos/pdf/matematica.pdf. Acesso em: 28/10/2017.

BRASIL. Parâmetros Curriculares Nacionais. Brasília, 2000. 109 p. Disponível em: http://portal.mec.gov.br/seb/arquivos/pdf/blegais.pdf. Acesso em: 13/11/2017.

CARNEIRO, M. M. F. Para uma educação filosófica: A pedagogia da pergunta de Paulo Freire e Antonio Faundez. Rev. Eros, São Paulo, v. 1, n. 1, p. 74-85, out-dez. 2013.

CHARLES, R.; SILVER, E. A. (Org.). The Teaching and Assessment of Mathematical Problem Solving. Reston: Lawrence Erlbaum, 1989.

COELHO, S. L. B. Pedagogia de Problemas. Manguinhos: Fundação Oswaldo Cruz, 2009. Disponível em: http://www.sites.epsjv.fiocruz.br/dicionario/verbetes/pedpro.html. Acesso em: 10/06/2017. 
CORRADI, D. K. S. Investigações Matemáticas mediadas pelo Pensamento Reflexivo no Ensino e na Aprendizagem de Funções Seno e Cosseno: Uma experiência com alunos de $2^{\circ}$ ano do Ensino Médio. 2013. 208 f. (Mestrado)-Educação Matemática, Universidade Federal de Ouro Preto, Ouro Preto, 2013.

D’AMBRÓSIO, U. Prefácio. In: ONUCHIC, L. R.; LEAL JUNIOR, L. C.; PIRONEL, M. (Org.). Perspectivas para Resolução de Problemas. São Paulo: Livraria da Física, 2017. p. 9-12.

DEWEY, J. How we Think. 1. ed. Boston: D. C. Heath \& CO. Publishers, 1910. 242 p.

ERNEST, P. The Philosophy of Mathematics Education. 1. ed. Londres: Falmer Press, 1991.

ERNEST, P. Problem Solving: Its Assimilation to the Teacher's Perspective. In: PONTE, J. P.; MATOS, J. F.; FERNANDES, D. (Org.). Mathematical Problem Solvina and New Information Technologies: Research in Contexts of Practice. Berlin: Srpinger-Verlag, 1992. v.89 (Research in Contexts of Practice),

ERNEST, P. The Psychology of Learning Mathematics: The cognitive, affective and contextual domains of Mathematics Education. Alemanha: Lampert Academic Publishing, 2011.

FERREIRA, M. J. A.; ALENCAR, A. C. A construção de um obejto matemático ideal. In: PINHEIRO, J. M. L.; LEAL JUNIOR, L. C. (Org.). Perspectivas das quais se visa a Matemática e seu ensino: Possibilidades que se abrem à Educação Matemática. São Paulo: Livraria da Física, 2018. v.No Prelo, cap. 2, p. 14.

FOUCAULT, M. As palavras e as coisas: uma arqueologia das ciências humanas. 8. ed. São Paulo: Martins Fontes, 1999.

FOUCAULT, M. A Ordem do Discurso. 24. ed. São Paulo: Loyola Ed., 2014. 78 p.

FOUCAULT, M. Arqueologia do Saber. 8. ed. Rio de Janeiro: Forense Universitária Ed., 2015.

FREIRE, P. Pedagogia da autonomia: saberes necessários à prática educativa: Coleção Leitura. 25. ed. São Paulo: Paz e Terra, 1996.

FREIRE, P.; FAUNDEZ, A. Por uma pedagogia da pergunta. Rio de Janeiro: Paz e Terra, 1985.

LEAL JUNIOR, L. C.; ALLEVATO, N. S. G. Momento Pedagógico e Pedagogia da Pergunta: Deslocamento conceitual para a prática em Resolução de Problemas. In: PINHEIRO, J. M. L.; LEAL JUNIOR, L. C. (Org.). Perspectivas das quais se visa a Matemática e seu ensino: Possibilidades que se abrem à Educação Matemática. São Paulo: Livraria da Física, 2018.

LEAL JUNIOR, L. C.; ONUCHIC, L. R. Ensino e Aprendizagem de Matemática Através da Resolução de Problemas Como Prática Sociointeracionista. Bolema: Boletim de Educação Matemática, v. 29, n. 53, p. 955-978, 2015.

MACHADO, E. S. Modelagem matemática e resolução de problemas. 2006. 140 f.(Mestrado)Faculdade de Física, PUC/ RS, Porto Alegre, 2006.

MACHADO, N. J. O Conhecimento como um valor. 1. ed. São Paulo: Livraria da Física, 2015. MACHADO, N. J.; D'AMBRÓSIO, U.; ARANTES, V. A., Eds. Ensino de Matemática: Pontos e contrapontos. São Paulo: Summus Editorialed. 2014.

MEIRIEU, P. La pédagogie entre le dire et le faire: le courage des commencements. Paris: ESF Éditeur, 1995. 
MORAIS, R. S.; ONUCHIC, L. R.; LEAL JUNIOR, L. C. Resolução de Problemas, uma matemática para ensinar? In: ONUCHIC, L. R.; LEAL JUNIOR, L. C.; PIRONEL, M. (Org.). Perspectivas para Resolução de Problemas. São Paulo: Livraria da Física, 2017. v.1, cap. 13, p. 397-432.

MORO, A. L. F. Construtivismo e educação matemática. Educ. Mat. Pesqui., São Paulo, v. 11, n. 1, p. 117-144, 2009.

ONUCHIC, L. R. et al. Resolução de Problemas: Teoria e Prática. 1. ed. Jundiaí: Paco Editorial, 2014.

PIMENTA, S. G. Para uma re-significação da didática. In: PIMENTA, S. G. (Org.). Didática e formação de professores: percursos e perspectivas no Brasil e Portugal. São Paulo: Cortez Ed., 2000. p. 19-76.

PINHEIRO, J. M. L.; LEAL JUNIOR, L. C.; FERREIRA, B. L. Escola e aulas de Matemática: ambiente de ser o que se é ou de ser o que está? Acta Scientiae, Canoas, v. 19, n. 2, p. 193-210, mai/abri. 2017.

POLYA, G. How to solve it: A new aspect of mathematical method. Princeton: Princeton University Press, 1945.

POLYA, G. Mathematics and Plausible Reasoning. 2. ed. Princeton: Princeton University Press, Vol. 2, 1968. (Paterns of plausible inference).

POLYA, G. Mathematics and Plausible Reasoning. Princeton: Princeton University Press, Vol. 1, 1954. (Induction and analogy in mathematics).

POSSAMAI, J. P.; CARDOZO, D.; MENEGHELLI, J. Concepções dos professores de matemática quanto a utilização de exercícios, situações contextualizadas e problemas. Amazônio: Rev. de Educação em Ciências e Matemática. v. 14. n. 31. 2018. p. 73-88.

SKOVSMOSE, O. Critical Mathematics Education: Concerns, Notions, and Future. In: AL., E. E. (Org.). The Philosophy of Mathematics Education, ICME-13 Topical Surveys. Hamburgo: Springer Open, 2016. p. 9-13.

SKOVSMOSE, O. Foregrounds: Opaque stories about learning. Rotterdam: Sense Publishers, 2014a.

SOUZA, M. C. R. F.; FONSECA, M. C. F. R. Relações de gênero, Educação Matemática e Discurso: Enunciados sobre mulheres, homens e matemática: Tendências em Educação Matemática. Belo Horizonte: Autêntica Editora, 2010. 159 p.

STANIC, G. M. A.; KILPATRICK, J. Historical perpectives on problem solving mathematics curricula. In: CHARLES, R.; SILVER, E. A. (Org.). The Teaching and Assessment of Mathematical Problem Solving. Reston: Lawrence Erlbaum, 1989.

VEIGA-NETO, A. Foucault \& Educação. 3. ed. Belo Horizonte: Editora Autêntica, 2011. 159 p.

VERGNAUD, G. La théorie des champs conceptuels. Recherches en Didactiques des Mathématiques, v. 10, n. 23, p. 133-170, 1990b.

WAGNER, G.; SILVEIRA, E. Reflexões Ontológicas em Educação Matemática: Heidegger e a perspectiva da Educação Matemática Crítica. Revista de Educação, Ciências e Matemática, Rio de Janeiro, v. 7, n. 2, p. 173-193, mai-ago. 2017.

ZANOTTO, M. A. C.; DE ROSE, T. M. S. Problematizar a própria realidade: análise de uma experiência de formação contínua. Educ. Pesqui., v. 29, n. 1, p. 45-54, jan-jun. 2003. 